\title{
A forma verbal éste na lírica profana galego-portuguesa*
}

\author{
Manuel Ferreiro \\ Universidade da Coruña
}

\begin{abstract}
Resumo:
Neste artigo estúdase exhaustivamente a aparición e o uso de éste, forma concorrente con é, P3 do presente de indicativo de seer, na lírica profana galego-portuguesa. A través da revisión sistemática da súa aparición nos manuscritos, fica demostrada a súa vixencia na lingua literaria galego-portuguesa, así como a inexistencia dunha forma latinizante est que tradicionalmente fora estabelecida en numerosas edicións da lírica galego-portuguesa.
\end{abstract}

\section{Palabras chave:}

Galego-portugués, edición, lírica trobadoresca, formas verbais, éste.

\begin{abstract}
:
The aim of this article is to analyse the appearance and use of éste, concurrent form with é, third-person present indicative of seer, in Galician-Portuguese profane lyric poetry. Its validity and relevance in Galician-Portuguese literary language is proved by means of the systematic revision of its appearance in manuscripts. This revision also demonstrates the non-existence of a Latinate form est, which had been traditionally established in numerous editions of Galician-Portuguese lyric poetry.
\end{abstract}

Key words:

Galician-Portuguese, edition, troubadour lyric poetry, verbal forms, éste.

\section{Introdución}

Desde as primeiras edicións dos textos do corpus trobadoresco galego-portugués, poden rastrexarse comentarios sobre a forma de terceira persoa do verbo seer, que presentaba dous resultados a partir do latín EST. O primeiro, e maioritario, é produto

\footnotetext{
* * Este traballo inscríbese no proxecto de investigación coordinado Cancioneiros galego-portugueses. Edición crítica e estudo (en formato impreso e electrónico). Subproxecto UDC: As cantigas de segundo cancioneiro aristocrático galego-portugués (PGIDIT06CSC20401PR), subsidiado pola Dirección Xeral de Innovación Tecnolóxica da Consellería de Industria da Xunta de Galicia. Unha versión inicial do presente artigo foi presentada no XII Congreso da Asociación Hispánica de Literatura Medieval (Cáceres, 2007).
} 
dunha evolución analóxica a partir dunha hipotética forma inicial *es, desaparecida pola inevitábel confluencia coa segunda persoa $(\angle E S)$ a través da nivelación, con perda de $-s$ (despois de desaparecer o - $\mathrm{T}$ final latino), con todas as terceiras persoas verbais, sempre acabadas en vogal nos verbos regulares e na maioría dos verbos irregulares. Alternativamente, no noso corpus trobadoresco aparece tamén unha forma éste que presenta unha vogal final de apoio sobre a base latina.

E así é descrito xa desde D. Carolina Michaëlis de Vasconcelos, que, cando explica a forma éste no glosario do Cancioneiro da Ajuda, afirma que "é a forma latina, a que os trovadores acrecentaram - $e$ paragógico, visto que $-t$ não podia ser final de sílaba ou palavra em vocábulos aportuguesados. Claro que conta por duas sílabas" (Michaëlis 1990, I: s.v. éste) ${ }^{1}$. Mais, por outra parte, na glosa da forma est, a ilustre estudosa indica tamén que "essa forma latina da 3 p. do pres. ind. do verbo esse foi empregada pelos trovadores tanto antes de vogal como antes de consoante e em fim de orações" (Michaëlis 1990, I: s.v. est).

Como se pode observar, Michaëlis considera a posibilidade dunha forma directamente latina ou latinizante est perante consoante ou en final de oración ${ }^{2}$, que unha revisión exhaustiva do corpus da lírica profana desmente, porque da análise de todos os contextos en que tal forma sería posíbel só se pode deducir que a variante éste é a única forma verdadeira e real alternativa á xeral é, aínda que moitas veces se rexistre con perda da vogal final por crase co vocábulo seguinte ${ }^{3}$.

A pesar do recoñecemento teórico da existencia desta forma verbal éste, a práctica da maioría dos editores da nosa lírica medieval foi a de evitar tal forma, sempre sentida como excepcional, a pesar da súa documentación firme na prosa cronística (Lorenzo 1974: s.v. seer), na prosa notarial (Maia 1986: 814-817) e, sobre todo, nas Cantigas de Santa Maria, que reflicten un uso absolutamente paralelo ao da poesía profana, cunha distribución complementaria da forma éste (moitas veces tamén en crase coa vogal seguinte) e da forma analóxica e maioritaria é. Consecuentemente, Mettmann (1972: s.v. seer) introduce un necesario til diacrítico, ao contrario de moitos dos editores do corpus profano, nomeadamente algúns de orixe italiana, que non marcan graficamente tal crase por consideraren que estamos perante un "latinismo relativamente frequente nei canzonieri" (Spampinato 1987: 91).

1 Na realidade, neste glosario só se recollen dous casos de éste, un deles a partir da corrección feita por Nobiling (1097: 355) nas súas observacións á edición do Cancioneiro da Ajuda (véxase nota 3).

2 Talvez por iso é contraditoria no uso gráfico do apóstrofo (est'), só presente en dous dos dez casos citados no seu glosario.

3 Para unha crítica da política editorial de Carolina Michaëlis arredor desta forma (con solucións contraditorias tanto gráfica como interpretativamente), véxase Nobiling (1907: 355), que corrixe a edición desta forma verbal nas cantigas 71, 89, 130, 182, 184, 197, 207 e 223. 
Neste artigo pretendemos, pois, revisar exhaustivamente a utilización da forma éste (e ést'), que coidamos, como xa dixemos, única alternativa á xeral é, a partir dos contextos dos manuscritos en que tal forma sería posíbel ${ }^{4}$. Para a forma con crase da vogal final, partimos do estudo das secuencias <est + vogal>, onde sobrancean os problemas interpretativos da secuencia <esta $>$, que pode ser lida como simple demostrativo feminino, como P3 do presente de indicativo de estar, ou, finalmente, como o encontro da forma verbal éste co art. $a$ e mais coa prep. $a^{5}$.

\section{2. Éste na lírica profana galego-portuguesa}

No corpus profano, éste aparece en múltiplos contextos precedendo un vocábulo iniciado con vogal, o que provoca, en xeral, a crase coa vogal final da forma verbal. O cómputo de todos os casos da poesía trobadoresca profana revela que tal crase se rexistra perante todas as vogais, sendo especialmente frecuente co adverbio assi, que parece suxerir certa resistencia ao encontro de é con este adverbio, como mostra que no corpus se documenten escasísimas ocorrencias deses contextos.

Do punto de vista cuantitativo, a crase da forma éste aparece frecuentemente perante as formas $o, a$ do artigo ${ }^{6}$ : 86 JSrzSom [A20, B113], v. 2: atal ést' o meu sén <est ol> AB; 94 JSrzSom [A28, B121], v. 13: quen / ést' a dona <esta> A, <est al> B; $106 \mathrm{NuEaCer}$ [B133], v. 24: qual ést' o ben melhor <esto> B; 128 MartSrz [A41, B153], v. 5: e essa ést' a mia senhor <esta> A, <est al> B; 181 PGarBu [A91 (vv. 1-24), B195], v. 26: qual ést' o ben <est o> B; 186 PGarBu [B200], v. 5: ést' a máis fremosa que no mund' á <est al> B; 187 PGarBu [B201], v. 3: qual ést' a dona que me faz morrer <est al> B; 196 PGarBu [A103, B211], v. 2: u ést' a mui fremosa mia senhor <est a> A, <est al> B; 197 PGarBu [A104, B212], v. 21: que ést' o máis que me tolher podia! <est ol> A, <estol> B; 199 PGarBu [A106, B214-215], v. 2: qual ést' a dona que quero gran ben <est ál> A, <est al > B; v. 13: qual ést' a dona que me faz assi <est al> A, <est a> B; 213 FerGaEsg [B229], v. 2: u ést' a molher que gran ben / quer <est al> B; 248 RoiQuei [A142, B263], r3: ést' a dona que me mata <esta> AB; 339 AfMdezBest [B377], v. 20: que ést' a peor / cousa <esto> B;

4 Para as referencias ás cantigas, utilizamos o sistema de Jean Marie D’Heur, coas correccións incorporadas por Montero Santalla (2001: 55-101). Os criterios de edición utilizados son os propostos en Ferreiro / Martínez Pereiro / Tato Fontaíña (2007).

5 Unha secuencia como está', crase de está co art. $a$ é certamente rara, aínda que se pode documentar en Joan Airas (945 [B942, V530], v. 9), conforme foi estabelecido na súa edición crítica (Rodríguez 1980: 57, 59).

6 Na transcrición dos manuscritos (A, B, V, T) desenvolvemos em itálica as abreviaturas que poden provocar dificultades tipográficas. A barra vertical indica o principio e/ou final da secuencia manuscrita. 
358 FerGvzSeav [A221, B389], v. 13: u ést' a mui fremosa mia senhor <est al> A, <esta> B; 360 FerGvzSeav [B391, V1], v. 4: qual ést' a dona que eu quero ben <est al> BV; 496 Den [B498, V81], v. 16: u ést' a melhor / de quantas son <esta a> B, <est a> V; 562 Den [B545, V148], v. 17: qual ést' o vosso <estol> BV; 583 Den [B566, V169], vv. 2, 5, 7, 10: e oj' ést' o prazo saido / passado <lest o / lesto > BV; 663 NuFdzTor [B648/V249], v. 2: qual ést' o voss' amigo <esso> BV; 692 JPrzAv [A184, B677, V279], r2: qual ést' a dona que me faz morrer <est a > A, <est al> B, <est a> V; 742 RoEaVasc [B727, V328], v. 17: e direi eu qual ést' a que o diz <est al> BV; 759 JGarGuilh [B743, V345], r1: aqueste mundo x' ést' a melhor ren <esta> B, <lesta> V; $871 \mathrm{AiNz}$ [B880, V463], v. 13: u ést' a dona que ren non quer dar / por min <est al> B, <est a > V; 973 AfEaCot [B971, V558], v. 16: a sa beldad' ést' a maior <lest a> BV; 1074 BernBon [B1072, V663], v. 6: e pero x' ést' a mia coita maior <lesta> BV; 1088 PArm [B1085, V677], v. 3: quen / ést' a dona que quero ben $<$ Est al> B, <est a > V; 1091 PArm [B1089, V680], v. 18: quen / ést' a dona que m' assi faz morrer <Esta $>$ B, <esta $>$ V; 1113 GalFdz [B1111bis, V702], v. 14: quen ést' a que loei <est al> BV; 1117 Lour [B1115, V706], v. 9: d' u ést' a mia senhor <est al> BV; 1235 PEaSol [A282, B1219, V824], vv. 1, 7: Non ést' a de Nogueira <esta> $\mathrm{AB},<$ est al $>\mathrm{V} /<$ est a $\mathrm{A},<$ esta $>\mathrm{B},<$ est al> V; 1289 MartGi [B1272, V878], r2: ca ja i ést' o que namorei <esto> BV; 1580 EstFai [B1561], v. 4: per quant' ést' o que vos quero dizer $<$ est $^{\mathrm{s}} \mathrm{O}>\mathrm{B}^{7} ; 1672$ PAmigo [B1660, V1194], v. 16: qual ést' o mundo <esto> BV; 1682 PAmigo [V1204], r: que al ést' a candea e al ést' o candeo $<$ est a ... est $\mathrm{o}>\mathrm{V}$.

Do mesmo xeito, documéntase unha forma éste contraída coa forma el do artigo: 1348 JSrzPav [B1330bis, V937], v. 2: pois en Proenç' ést' el-Rei d' Aragon <lest el> BV.

Igualmente, aparece perante o substantivo ome en dúas cantigas (96 JSrzSom [A30, vv. 1-7, B123], v. 20: ca non ést' om' en seu poder <estome> B; 346 FerGvzSeav [A210], v. 15: ne[n] ést' ome nado / que o soubesse <est ome> A. E tamén a mesma crase de éste se produce con diversos participios: amada (274 JSrzCoe [A166, B318], v. 6: porque ést' amada < est amada> AB), aguisado (1502 AiPrzVuit [B1482, V1093], v. 4: que ést' aguisado <est aguysado> BV; 1471 JGai [B1452, V1062], v. 4: $\mathrm{O}$ jantar ést' aguisado <esta guisado $>\mathrm{B}$, <esta grisada $>\mathrm{V}^{8}$ ); acustumado (1503 AiPrzVuit [B1483, V1094], v. 1: Don Martin Galo ést' acustumado <est acustumado> BV), aventurado (1555 Den [B1536], v. 24: mais se el fica ... / ...

\footnotetext{
7 A abreviatura espuria podería ser un erro por til sobre $t$, coa conseguinte modificación de lectura: "per quant' éste o...".

8 Arrastrado pola lección manuscrita <esta guisado> de B, Lapa (1970: 304) transcribe está guisado, en lugar de ést' aguisado, como na cantiga anterior.
} 
ést' aventurado <est auenturado>; 1606 PGarAm [B1596], v. 1: vej' eu que ést' aventurado <est auenturado> B), omiziada (1588 PGarAm [B1578], v. 1: Maior Garcia ést' omiziada <estomizia/da> B) e apartado (1643 PPon [B1631, V1165], v. 8: E ben creede que ést' apartado <esta partado > B, <estapartado > V).

Por outra parte, éste aparece perante diversas formas do demostrativo: 119 PaiSrzTav [A33, B148], v. 19: E, de pran, ést' est' o maior / ben <est est ó> A, <e esto> $\mathrm{B}^{9}$; 482 Alf $\mathrm{X}$ [B484, V67], v. 27: mais muit' ést' aquesto peior <lesta questo> B, <lestaquesto> V; 526 Den [B528, V111, T5], v. 2: que est' aquel' en que vos mereci <est aquell> BVT; 823 AfEaCot [B825, V411], r1: que ést' aquest' ou por que o fazedes <estaquestl> BV; 1468 JGaia [B1449, V1059], v. 9: u ést' aquela que sa vida ten / en seu poder <est aquela > B, <est aquela > V; 1671 PAmigo [B1659, V1193], v. 13: U ést' essa conca bispal <estessa> BV.

E tamén se rexistra crase co pronome persoal el (1389 NuFdzTor [B1371, V979], v. 12: ca tal ést' el <est el> BV), do mesmo modo que con outras formas pronominais: al (821 VaPrzPard [B824, V409], v. 17: sei eu que non ést' al <estal> BV), atal (97 JSrzSom [B124], v. 21: gran coita per-ést' atal <per esta tal> B; 222 FerGaEsg [A122, B238], v. 8: e meu sén ést' atal <est atal> A, <en tal> B; 1239 JBav [B1223/ V828], v. 15: meu sen est' atal <est atal> BV) e ũa (1597 AfEaCot [B1587, V1119], v. 7: E non ést' ũa velha <estũa> BV).

Mais é, sen dúbida, especialmente frecuente esta crase co adverbio assi, rexistrándose no corpus profano numerosos encontros que adquiren valor formulístico ${ }^{10}: 78$ JSrzSom [B105], v. 6: e se non ést' assi <esta assy> B; 132 MartSrz [A45, B157], v. 15: Pois ést' assi <est assi> A, <estassi> B; 195 PGarBu [A102, B209-210], v. 29: se non ést' assi <est assi> A, <est assy> B; 291 RoEaRed [B331 e 335], v. 16: pois ést' assi <est assy> B; 318 JLpzUlh [A207, B358], v. 9: e pero ést' assi <est assi> A, <lestassy> B; 326 FeFdzCog [B366], v. 10: vedes ... que ést' assi <est assy> B; $328 \mathrm{RoEaVas}$ [B367], v. 17: dizedes que non ést' assi <est assy> B; 329 RoEaVasc [B368], v. 9: sabe Deus de nós que ést' assi <esta ssy> B; 338 AfMdezBest [B376], v. 15: e pois ést' assi <est assy> B; 400 EstFai [A240, B428, V40], v. 9: diredes que non ést' assi <est assi> A, <est assy> BV; 405 JVqzTal [A244, B432, V44], v. 15: e, de pran, ést' assi <est assi> A, <estassy> BV; 419 FerVelh [A260, B437, V49], v. 3: e ja que ést' assi <est assi> A, <est assy> BV; 435 Anónimo [A270], v. 8: podedes entender / que ést' assi <est assi> A; 509 Den [B511, V94], v. 13: Grave vos ést', assi Deus mi perdon <estassy> BV; 552 Den [B535, V138], v. 16: pois

9 É obvio que B xa implica unha forma é.

${ }^{10}$ A secuencia é assi unicamente aparece en 509 Den [B511, V94], v. 7; 754 AfLpzBai [B738bis, V340], v. 4; 808 PaiGmzCha [B812, V396], v. 9; 924 PGot [B921, V509], v. 12; 1224 PAmigo [B1208, V813], v. 14. 
que ést' assi <estassy> BV; 557 Den [B540, V143], v. 5: pois ést' assi <estassy> BV; 604 Den [B587, V190], v. 4: pois ést' assi <est assy> BV; v. 10: pois ést' assi <est assy> BV; v. 16: pois ést' assi <estassy> BV; 636 EstGuar [B621, V222], v. 9: non ést' assi <estassy> BV; 771 JGarGuilh [B754, V357], v. 4: cuido que non ést' assi <est assy> BV; 806 PaiGmzCha [B810, V394], v. 10: e pero ést' assi <estassy> BV; 944 SanSchz [B941, V529], r1: sabe ben que ést' assi <esta ssy, estassy, estassy> BV; 975 AiEng [B973, V560], v. 17: nen sei que x' ést', assi m' aven <lestassy> BV; 1029 JAi [B1025, V615], r2: e semelha-mi que non ést' assi <estassy> BV; 1054 JAi [B1052, V642], v. 1: pois que vos ést' assi <est assy> BV; 1154 JServ [B1150, V743], r1: creo que non ést' assi <estassy> BV; 1530 FerGarEsg [B1511], v. 14: mais por que ést' assi <estassy> B; 1588 PGarAm [B1578], v. 17: non ést' as[s]i <estasy> B; 1591 AfEaCot [B1581, V1113], v. 5: Se ést' assi <esta ssy> BV.

Para alén de con assi, éste aparece en crase con outras formas adverbiais, como aqui (789 JVqzTal [B792, V376], r1: que ést' aqui e quer migo falar <est aquj> B, <est aqui> V; 798 MenVqzFolh [B802, V386], v. 11: meu amigo, que ést' aqui <est aqui> BV; 1385 MartSrz [B1367, V975], v. 1: un mour' ést' aqui / fugid', e... <lestaqui> BV), oje (107 NuEaCer [B134], v. 26: ca este ést' oje o maior / ben <estoie> B; 1100 PAmigo [B1098, V689], v. 27: que non ést' oj' outra no mundo nada <estoil> BV), ar (1069 BernBon [B1067, V658], v. 9: e non ést' ar de vós melhor <estar> V), ora (957 JAi [B954, V542], v. 1: Que grave m' ést' ora de vos fazer <lestora> BV), $u$ (712 JLpzUlh [B697, V298], r: ala ést' u el é <est hul> BV) e $i$ (1652 PPon [B1640, V1174], v. 20: per-ést' i / quen tal ome por rico ten <per esty> BV).

A crase de éste tamén se produce coas preposicións a (172 PGarBu [A82, B186a], v. 22: E quant' oj' ést', a meu coidar, / ben per-sei eu ca non á i / coita maior ... <lest a> AB; 509 Den [B511, V94], r2: grav' ést' a mí <lest al> BV) e antre (97 JSrzSom [B124], v. 25: ca non ést' antre nós igual / est' amor <estantre> B).

Do mesmo xeito, son frecuentes os contextos de crase de éste coa conxunción $e$ (véxase máis abaixo) e mais coa conxunción ou (179 PGarBu [A89, B193], v. 27: Joana ést' ou Sancha, ou Maria <est. ou>A, <est e> B ${ }^{11}$; 680 JPrzAv? [B665, V267], v. 13: Non sei que x' ést' ou que pode seer <lestou> BV). Finalmente, éste tamén aparece en crase coa interxección ai! (1162 JZor [B1149a, V752], v. 3: Quen ést', ai filha <estay> BV).

Mais é na secuencia <este> onde aparecen os maiores problemas para a correcta interpretación dos manuscritos, porque, na realidade, subxacen varias lecturas posíbeis:

11 A lección de B (<Iohana est e Sancha e Maria>) implica crase con conxunción $e$. 
(a) este (demostrativo) e, tamén, est'e (demostrativo + conx. $e)^{12}$;

(b) esté (P1 ou P3 do presente de subxuntivo de seer) ${ }^{13}$;

(c) éste (P3 do presente de indicativo de seer), est'é (demostrativo + é) e ést'e (forma verbal éste + conx. e).

Normalmente, a interpretación de <este> como forma verbal éste en crase coa conxunción $e$ non presenta graves problemas de aceptación: 218 FerGarEsg [A118, B234], v. 4 (mia senhor ést', e senhor das que vi) ${ }^{14}$; 333 PMaf [B371], v. 13 (De vos pesar, senhor, ben ést' e prez); 367 MenRdzTen [B399, V9], v. 16 (mais cuid'eu a ir / u ela ést', e non poss'...; 812 PaiGmzCha [A248 e 253, B816, V400], v. 23 (que o ben ést', e faz gran traicion) ${ }^{15}$; 956 JAi [B953, V541], v. 9 (...meu mal ést', e cuido gran razon); 1247 JBav [B1231, V836], v. 16 (pera ir / u ela ést', e a vós non aven); 1679 PAmigo [V1201], v. 9 (contra quen sabe ond' ést' e onde non / é seu barnagen...).

Nos restantes casos que din respecto a este levantamento (éste, est'é) a situación é máis complexa por canto se percibe na maioría dos editores certa resistencia á consideración da presenza desta forma verbal éste, que é sentida como anómala, favorecendo unha interpretación da secuencia <este> como a crase da forma demostrativa de primeira persoa coa forma verbal é (est'é). Do levantamento,

12 O demostrativo coa conx. $e$ aparece nas cantigas 62 VaFdzSend [B89], v. 7; 80 JSrzSom [A14, B107], v. 25; 222 FerGaEsg [A122, B238], v. 9; 246 RoiQuei [A140, B261], v. 15; 255 VaGil [A147, B270], v. 10; 265 JPrzAv? [A157], v. 21; 266 JSrzCoe? [A158], v. 10; 282 JSrzCoe [A175, B326], v. 4; 286 JSrzCoe [A179, B330], v. 9; 320 JLpzUlh [A209, B360], v. 15; 393 JGarGlh [A228, B418 e 426, V29 e 38], v. 22; 460 GarPrz [B465], v. 19; 697 JSrzCoe [B682, V284], v. 14; 896 MartMo? [A304], v. 9; 1116 Lopo [B1114, V705], v. 4; 1534 GilPrzCo [B1515], vv. 11, 14.

${ }^{13}$ Esta forma verbal semella escasa no corpus: 497 Den [B499, V82], v. 14; 1359 LoLias [B1342, V949], vv. 5, 15; 1588 PGarAm [B1578], v. 21. A estas ocorrencias hai que, na nosa opinión, acrecentar esté en 1113 GalFdz [B1111bis, V702], v. 8 (Teen-m'en tal coita que nunca vi / om'en tal coita, pero o preit'esté: / que lhis diga por quen trob'e quen é), tradicionalmente editado como est'é; mais a aparición da é en rima no v. 9 aconsella considerar a forma esté para transcribir a secuencia <este> de BV no verso anterior.

14 Así é editado este verso en Michaëlis e Spampinatto, mais a estrofa permite unha lectura diferente, coa presenza da forma plena de éste:

A melhor dona que eu nunca vi, per bõa fe, nen que oi dizer, é a que Deus fez melhor parecer: mia senhor éste senhor das que vi, de mui bon preço e de mui bon sén.

${ }^{15}$ De novo é posíbel outra lectura que manteña a integridade de éste:

E de qual eu, senhor, ouço contar que o ben éste: faz gran traicion o que ben á, se o seu coraçon en al pon nunca senon en guardar sempr' aquel ben ... 
que pretendemos exhaustivo, de todas as secuencias posíbeis, tíranse os seguintes resultados:

1. Existe un grupo de cantigas en que consideramos certa a presenza de éste, en principio sempre perante consoante, aínda que existan solucións contraditorias e, por veces, incomprensíbeis en diversos editores ${ }^{16}$. A súa aparición prodúcese normalmente en contextos negativos e tamén noutros onde evitar éste esixiría considerar unha posposición do demostrativo ao nome que no corpus trobadoresco nunca se produce ${ }^{17}$ :

64 VaFdzSend [A1, B91], v. $15<$ este> A, <esta $>$ B ${ }^{18}$

Ca non éste cuita d' amor

ũa que ome filhar ven.

197 PGarBu [A104, B212], v. $18<$ este> A, <est> B ${ }^{19}$

tolhe-mi o corpo que ja nunca dia

éste, nen noite, que aja sabor

de min, nen d' al! ...

223 FerGaEsg [A123, B238bis], r1: <est e / est é> A, <hee / é> B ${ }^{20}$

E se assi non éste, mia senhor,

non me dé vosso ben, nen voss' amor!

${ }^{16}$ Consideramos unicamente as edicións da vulgata e mais as edicións críticas máis recentes, case todas elas incorporadas á compilación de Brea (1996), o cal simplifica as referencias bibliográficas.

Non consideramos outras versións das cantigas trobadorescas que poden presentar formas sen fundamento textual, como ocorre, por exemplo, no v. 5 da cantiga 888 MartMo [B896/V481], que na edición de Videira Lopes aparece como "o cor m'est [t]am tejo", fronte ás lecturas “o cor m'está 'n tejo" (Stegagno Pichio 1968: 179) ou “o cor mostr'antejo” (Lapa 1970: 420).

${ }^{17}$ En todo o corpus só localizamos un caso claro de posposición, nunha pasaxe certamente confusa na cantiga 1430 [V1020], v. 18:

-Pero Martiiz, mui ben respondestes, pero sabia-m'eu esto per min, ca todos tres eran senhores $\mathrm{i}$ das comendas, comendadores estes,

e partistes-mi-o tan ben, que m'é mal.

18 A lección de B é diverxente, implicando unha crase da forma verbal co art. feminino ("E quant' ést' a coita d' amor ...").

${ }^{19}$ A versión inicial de Michaëlis (esté) xa foi rectificada pola propia autora no glosario, após a crítica de Nobiling (1907: 355).

${ }^{20}$ A interpretación de Michaëlis (1990, I: 252), que xa fora corrixida por Nobiling, é seguida na edición de Fernan Garcia Esgaravunha realizada por Spampinatto (1987: 113):

E se assi non est'é, mia sennor,

non me dê vosso ben ne voss'amor! 
266 JSrzCoe? [A158], v. 20: <este> A ${ }^{21}$

Catade, senhor, non vos éste mal, ca polo meu non vos venh' eu rogar.

1230 PAmigo [B1214, V819], v. 13: <este> BV 22

O cantar éste mui dito,

pero que o eu non sei.

1421 JPrzAv/JSrzCo [V1011], v. 14: <leste> V

e que x' é vosso Toled' e Orgaz,

e todo quanto se no mundo faz

ca por vós x' éste -dized[e-o] assi.

1569 JVqzTal/PAmigo [B1550], v. 13: <leste> B ${ }^{23}$

... por que non entendedes

que o seu preço e o seu valor

todo noss' éste pois emperador for?

1640 PPon [B1628, V1162], v. $12<$ este> BV 24

Eno abril, quando gran vento faz,

o abrigo éste vosso solaz.

Neste mesmo grupo debe ser incrito un amplo conxunto de textos en que os manuscritos, nomeadamente procedentes de $\mathrm{B}$, presentan unha forma <est> que xulgamos grafía de inspiración latinizante para éste, pois a presenza da vogal final é necesaria para a correcta contaxe métrica do verso:

${ }^{21}$ Michaëlis modificou a lección do Cancioneiro da Ajuda (<catade sẽnor nõ uos este mal> A), editando "Catade, senhor, per vós est’é mal.." (1990, I: 318). Para alén da edición que propomos, tamén é certo que <este> podería ser interpretado nesta pasaxe como esté, presente de subxuntivo de estar.

22 A lección éste é recollida na edición crítica do trobador (Marroni 1968: 266), fronte a unha primeira versión est'é de Nunes que corrixiu posteriormente nas notas ás Cantigas de Amigo (Nunes 1973, III: 294).

23 O verso é hipermétrico, o que explica a reconversión de éste en est en Michaelis (1990, II: 420) e Marroni (1968: 290): "Essendo il v. ipermetro, espungo la -e paragogica di este, come in Michaëlis. Il Cunha non rileva l' irregolarità di questo verso e stampa este". Cunha (1982: 158) suxire a mesma opción para a nivelación métrica do verso, que, en todo o caso, coidamos que debería contemplar a conversión de éste en é. Pola súa parte, a edición crítica deste trobador mantén a forma "este" (Fregonese 2007: 75).

24 Saverio Panunzio (1992: 135) transcribe incomprensibelmente "o abrigo, est é vosso solaz", coa seguinte nota: "est é, con é paragóxico. Braga: est o; Lapa: este, verbo". Pola súa parte, na edición de Juárez (1988: 220-22) o verso aparece como “o abrigo est' e vosso solaz”, mais coa tradución española de "el abrigo es vuestro solaz". 
182 PGarBu [A92, B196], v. $27<$ lest $>$ AB $^{25}$

ca nunca pesar prenderei, nen gran coita d' amor, nen d' al, nen saberei que $x$ ' ést[e] mal, nen mia morte non temerei.

184 PGarBu [A94 (vv. 1-2), B198], v. 15 <est> B

E pois que assi ést[e] ja, que vos Deus feze máis valer de quantas outras no mund' á, verdade vos quero dizer.

204 PGarBu [B220], v. 18: <est> B ${ }^{26}$ $\mathrm{E}$ des que a vi o primeiro dia non me guardei, nen fui ende sabedor, nen me quis Deus guardar, nen mia folia: non ést[e] meu coraçon traedor que mi-a depois conselhou a veer.

\section{PGarBu [B223], v. $11<$ lest> B}

Mais enquant' eu ja vivo for, por én non creerei que o Judas vendeu nen que por nós na cruz morte prendeu nen que filh' ést[e] de Santa Maria.

464 Alf X [B464bis], v. $24<$ lestl $>$ B $^{27}$

$\mathrm{Ca}$ o mal que vos foi ferir, aquele x'ést[e] o nosso.

${ }^{25}$ En A aparece un $e$ marxinal corrixindo o orixinal <est>. Obsérvese a complexa e artificiosa solución $x$ 'é 'ste de Michaëlis (1990, I: 195):

Nen saberei que x'é 'ste mal, nen mia morte non temerei!

${ }^{26}$ O mesmo que Michaëlis (1990, I: 803), Pierre Blasco (1984: 209-211) interpreta est[e] como forma demostrativa, despois de corrixir a lección <non> en nen (cf. as palabras do editor francés: "Il faut restituer ici la forme complète du démonstratif"):

E des que a vi o primeyro dia,

non me guardey, nen fui ende sabedor, nen me quis Deus guardar, nen mha folia, $\mathrm{n}[\mathrm{e}] \mathrm{n}$ est $<\mathrm{e}>$ meu coraçon traedor que mh a depoys conselhou a veer.

27 A versión de Nunes (1972: 54) está moi lonxe da lección manuscrita ("aquel'é meu e non vosso"), recuperada na edición crítica da poesía profana de Afonso X (Paredes 2001: 149), cunha lectura diverxente da que agora presentamos: 
714 JLpzUlh [B699, V300], v. 9: <est> BV ${ }^{28}$

El de pran que esto cuida, que ést[e] migo perdudo, ca, se non, logo verria, mais por esto m'é sanhudo.

854 MenRoBri [B858, V444], v. 12: <lest> BV

e pero que sei que lh' ést[e] mui greu, quer lhi pes, quer lhi praza, ende ja, se morto non, nunca me partirei.

1075 JServ [B1074, V664], v. 4: <est> BV 29

Un dia vi mia senhor, que mi deu atal amor que non direi, per u for, quen ést[e], per nulha ren: non ous' eu dizer por quen mi ven quanto mal mi ven.

1456 RoiPaezRib [B1437, V1047], v. 12: <lest> BV

Quen vee qual cozinha ten de carne, se s' i non deten, non poderá estimar ben se x'ést[e] carne, se pescaz.

1497 AiPrzVuit [B1477, V1088], v. 22: <lest> BV Diz Fernan Diaz: -Ben m' ést[e], porque oferi Monsanto.

1625 FerRdzRed [B1614, V1147], v. 1: <est> BV Don Pedro ést[e] cunhado d' el-Rei, que chegou ora aqui d' Aragon con un [e]speto grande de leiton.

Ca o mal que vos foi ferir aquele, x'este o nosso.

28 A edición de Nunes (1973, II: 120), en versos curtos, resolve a hipometría do verso doutro modo, obrigándoo a estabelecer unha forma est: El de pran que esto cuida, / que est [co]migo perdudo. Por outra parte, a solución de Rip Cohen (2003: 184), tamén aceptábel, é interpretar est [é], presente de subxuntivo de estar (véxase nota 13).

${ }^{29}$ Modificamos a interpretación tradicional deste verso en Nunes (1972: 432), que semellaba considerar a presenza da conxunción $e$ :

Hun dia vi mha senhor, que mi deu atal amor que non direy per hu for quen est'[e] per nulha ren non ous' eu dizer por quen mi ven quanto mal mi ven. 


\section{PPon [B1640, V1174], v. 2: <est> BV ${ }^{30}$ \\ D' un tal ricome ouç' eu dizer \\ que ést[e] mui ricom' assaz, de quant' en gran requeza jaz.}

\section{PPon [B1655, V1189], v. 17: <est> BV 31 \\ non ést[e] rei nen conde, \\ mais é-X' outra podestade.}

2. Un segundo grupo de cantigas presenta, na nosa opinión, a forma éste, aínda que tradicionalmente a secuencia vén sendo interpretada dun modo diferente, xa que, na maioría dos casos, se considerou unha forzada crase da forma demostrativa este ou esto coa forma verbal é, fundamentalmente desde a edición do Cancioneiro da Ajuda realizada por Carolina Michaëlis de Vasconcelos:

$71 \mathrm{VaFdzSend}[\mathrm{A} 8, \mathrm{~B} 98]$, v. 6: <este> A, <est> B ${ }^{32}$

ca se sabor avedes i, gran ben per-éste pora mí.

89 JSrzSom [A23, B116], v. 27: <este> A, <est> B ${ }^{33}$

E se lh' esto disser alguen, que éste mal, diga-lhe quen quis Deus fazer que non cuidasse.

294 RoEaRed [B334], v. 2: <este> B ${ }^{34}$

O que vos diz, senhor, que outra ren desejo no mundo máis ca vós éste o mui sobejo mentira[1] quen o diz ...

\footnotetext{
${ }^{30}$ Neste caso, na edición de Juárez (1992: 190), ést[e] é traducido ao español como 'fue'.

31 Seguimos a disposición métrica desta cantiga estabelecida por Montero Santalla (2001: 739-740). Na tradicional edición lapiana en versos longos (Lapa, 1970: 549), o ilustre editor modifica o orixinal <est> en é ("Trata-se certamente de erro, por é; de contrário, lendo éste, o verso teria mais uma sílaba"), respectado nas edicións de Panunzio e mais de Juárez, que afirma: "Las formas est y este concurren con é en los Cancioneros, constituyendo una alternativa métrica y fónica" (Juárez, 1992: 297).

32 A presenza da forma verbal éste, co reforzo per- semella indubitábel, fronte a unha interpretación "gran ben per est'é pora mí" (Michaëlis 1990, I: 19).

33 Cf. a edición de Michaëlis (1990, I: 52):

E se lh'esto disser' alguen, que est' é mal, diga-lhe quen quis Deus fazer que non cuidasse.

${ }^{34}$ Na edición de Michaëlis (1990, I: 825) estabelécese de novo unha crase entre demostrativo e é:

O que vos diz, senhor, que outra ren desejo no mundo mais ca vos, est'é o mui sobejo mentido que'-no diz...
} 
302 RoiPaezRib [A191, B342], v. 21: <est é> A, <est e> B ${ }^{35}$

Pero m' ela non ten por seu, mui gran verdade vos direi: meu mal éste quanto ben ei, e fora po-lo dizer eu, e vi-a tan ben parecer [que lhi non pudi ren dizer].

398 JGarGlh [A238], v. 21: <este> A ${ }^{36}$ Mais pois que ja non posso guarecer, a por que moiro vos quero dizer: "De alguen éste filha, de Maria".

536 Den [B519b, V122], v. 7: <este> BV 37 tenho que mi fariades gran ben de mi dizerdes quanto mal mi ven por vós, se vos éste loor ou prez.

617 Den [B600, V203], v. 10: <este> BV 38 Pois me de levar vejo que éste o seu desejo, pois que a el praz, praz-mi muito sobejo: est'é o meu solaz.

1658 PPon [B1646, V1180], v. 6: <este> BV ${ }^{39}$ -Seja-o Pedro Bodinho, que éste nosso vezinho tan ben come Pedr' Agudo.

35 Modificamos a puntuación e a interpretación -diverxente- deste verso nas edicións anteriores. Cf. "meu mal est e quanto ben ei; / e fora... (Michaëlis 1990, I: 375); "meu mal est'é, quanto ben ei, e fora..." (Barbieri 1980: 48).

${ }^{36}$ É esta unha solución provisoria, seguramente discutíbel, para unha pasaxe de difícil interpretación nesta cantiga de Joan Garcia de Guilhade, editado tradicionalmente como "diz alguen: "Est'é filha de Maria" (Nobiling 1908; Michaëlis 1990).

37 A edición de Lang (1972: 41), que estabelecía est'é, xa foi corrixida en Nunes (1972: 138) a prol de éste.

38 Tanto Lang (1972: 98) como Nunes (1973, II: 51) consideran a existencia da crase est'é neste verso como no refrán.

39 De novo aparece en Panunzio (1992: 181) a mesma forma est é e mais o mesmo comentario que na cantiga 1640, v. 12 (véxase nota 24). Neste caso, a forma editada por Juárez (1992: 239), novamente est'é, é traducida como "es". 
Noutros dous contextos, a secuencia foi interpretada como unha crase entre o demostrativo e a conxunción $e$, que xulgamos dificilmente xustificábel dun punto de vista sintáctico e interpretativo:

\section{JPrzAv? [A183], v. 22: <est é> A ${ }^{40}$ \\ E melhor éste, mais sera meu ben \\ de morrer cedo e non saberen quen \\ é por quen moir' e que sempre neguei. \\ 1097 PAmigo [B1095, V686], v. 13: <est e> BV 41 \\ Mais non o éste, pois quis Deus assi, que por seu nunca me quis receber.}

Finalmente, a secuencia <este> de BV foi lida como demostrativo por estudosos como Michaëlis, Panunzio ou Juárez nunha pasaxe onde coidamos que, de novo, debe ser interpretada como forma verbal de seer:

\section{PPon [B985, V572], v. 5: <Este $>$ B, <este $>$ V 42 \\ $\mathrm{O}$ mui bon rei que conquis a fronteira e acabou quanto quis acabar}

${ }^{40}$ A única posibilidade de interpretar a existencia da conxunción $e$ sería a consideración dunha construción copulativa reforzada e mais, extremadamente frecuente en galego moderno mais ausente do poesía dos trobadores: "E melhor est, e mais será meu ben, / de morrer..." (Michaëlis 1990: 361).

41 A consideración da conx. $e$ esixe forzar a sintaxe para ligar sintacticamente "Mais non o ést"” con sey no final da estrofa, como acontece na edición de Nunes (1972: 468-469), con deficiente puntuación, e de Giovanna Marroni (1968: 241-242):

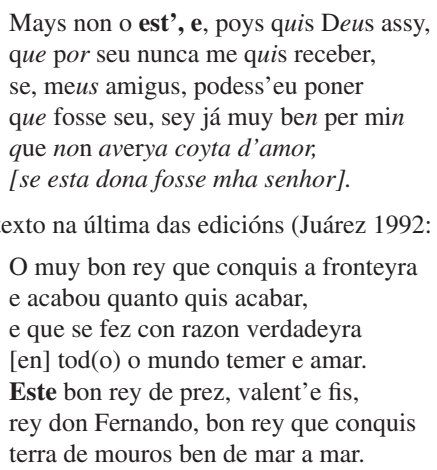

A interpretación de <este> como simple demostrativo nas edicións de Michaëlis, Panunzio e Juárez deixa toda a estrofa sen verbo principal, que necesariamente ten de residir nesa secuencia, que tamén podería ser lida como est'é. 
e que se fez con razon verdadeira [en] todo o mundo temer e amar éste bon rei de prez, valent' e fis, rei don Fernando, bon rei que conquis terra de mouros ...

3. Un terceiro grupo de cantigas presenta unha secuencia <este> en que semella razoábel -indubitábel en bastantes contextos- considerar a crase dunha forma demostrativa de primeira persoa (este, esta, esto) coa forma verbal é (est'é):

242 RoiQuei [A136, B257], v. 15: <esté> A, <este> B

Ca, de pran, est' é oje máis de ben

que ei, pero que sõo sabedor

que assi morrerei ...

276 JSrzCoe [A169, B320], v. 14: <est é>A

E se por est'é, mal dia naci!

887 MartMo [A307, B895, V480], v. 26: <est é>A

... mais, est' é meu mal,

contra mia desaventura

non val amar nen servir,

nen val razon nen mesura,

nen val calar nen pedir.

889 MartMo [B897, V482], v. 13: <este> BV

..., ca est' é o meu ben

e aquest' é meu viço e meu sabor!

971 AfEaCot/PPon [B969, V556], v. 22: <este> BV

-Afons' Eanes, est' é meu mester,

e per esto dev' eu guarecer

e per servir donas quanto poder.

1062 PVeer [B1060, V650], v. 17: <este> BV

e vós, fremosa mia senhor, nos vos queredes én doer

e por est' é meu mal viver, ai mia senhor, per bõa fe.

1114 Lopo [B1112, V703], v. 7: <este> BV

E non ach' eu razon e por est' é:

porque m' ei de guardar e de temer

de mi-o saberen, ... 
1237 JBav/PAmigo [B1221, V826], v. 32: <este> BV este faz mal, assi Deus me perdon, e est' é sandeo e estoutro non.

1281 Lour [B1265, V870], v. 13: <estel> BV

Ca est' é l'ome que máis demandava

e non ar quis que comigo falasse.

1381 MartSrz [B1363, V971], v. 19: <este> BV

E conselhava eu ben

a quen el don pedisse,

desse-lho log' e, per ren,

seu cantar non oisse,

ca est' é, ai meu senhor,

o jograr braadador

que nunca bon son disse.

1387 MartSrz [B1369, V977], v. 10: <este> BV

E pois a dona Caralhote viu

antre sas mãos, ouv' én gran sabor

e diz:-Est'é o falso treedor

que m' ogano desonrou e feriu.

4. Mais noutro amplo conxunto de cantigas existe a dupla posibilidade de lectura éste / est'é (e un contexto de éste / ést'e), ambas as dúas posíbeis sintáctica e semanticamente, aínda que na maioría dos contextos a segunda semella máis probábel:

65 VaFdzSend [A2, B92], v. 4: <este >A, <lest> B ${ }^{43}$

Senhor fremosa, grand' enveja ei

eu a tod' ome que vejo morrer,

e, segund' ora o meu conhocer,

enquant' est' é, faço mui gran razon.

130 MartSrz [A43, B155], v. 17: <este> AB ${ }^{44}$

E saberia d' algun ben mandado

de que oj' eu non sõo sabedor, mais sei que est' é desej' e cuidado.

\footnotetext{
43 A lección de B parece suxerir unha forma ést [e].

44 O verso permite outras lecturas alternativas: "mais sei que éste desejo e cuidado" (xa proposta por Nobiling en 1907), "mais sei que este desej' é cuidado".
} 
163 NuFdzTor [A74, B187], v. 13 <est e> A, <este ei> B ${ }^{45}$ Que prol vos á de eu estar sempre por vós en grand' afan? E est' é mui grande, de pran.

503 Den [B505, V88], v. 11: <este> BV ... sei per gran ben lhi querer máis ca min nen al, e, se aquest' é querer mal, est' é o que a min aven / ...

503 Den [B505, V88], v. 17: <este> BV ... se per servir e pe-la máis ca min amar, se est' é mal, a meu cuidar, este mal non poss' eu partir, / ...

568 Den [B551, V154], r2 <este> BV Por Deus, senhor, pois per vós non ficou de mi fazer ben, e ficou per mí, teede por ben, pois assi passou, en galardon de quanto vos servi, de mi teer puridade, senhor, e eu a vós, ca est'é o melhor.

617 Den [B600, V203], r2: <este> BV Pois que diz meu amigo que se quer ir comigo, pois que a el praz, praz a mí, ben vos digo: est'é o meu solaz.

634 EstGuar [B619, V220], v. 5: <este> B, <est el> V'6 e, mia senhor, est' é gran mal sobejo meu e meu gran quebranto:

45 A lección de B semella confirmar como correcta a interpretación est'é, mais tamén habería a posibilidade de lermos: "É este mui grande, de pran".

46 Pagani (1971: 78) recoñece que neste caso "non si può escludere però la lettura este", o cal levaría a unha outra puntuación do texto:

e, mia senhor, éste gran mal sobejo meu e meu gran quebranto seer eu de vós, por vos servir quanto posso, mui desamado. 
seer eu de vós, por vos servir quanto posso, mui desamado.

639 EstGuar [B624, V225], v. 10: <este> B, <est el> V

Ben entend' eu que logar deve aver o que ben serve de pidir, por én, ben con razon, mais est' é tan gran ben que lhi non pod' outro ben par seer.

782 JGarGuilh [B785, V369], v. 20: <este> BV -Vó-lo andades dizendo, amiga, est' é verdade, / ...

924 PGot [B921, V509], v. 12: <este> BV ... e, pero est' é assi, aven-m' ende o que eu non mereci: gran desamor que m' ela por én ten.

993 PPon [B990, V578], v. 24: <Est e> B ${ }^{47}$ Rei d'Aragon, rei do bon sén, rei de prez, rei de todo ben ést', e rei d' Aragon, de pran.

1272 GalFdz [B1256, V861], v. 20: <este> BV Veja-se vosc' e perderá pavor que á de vós, e est' é o melhor.

1403 PGarBu [B1384, V993], v. 18: <este> BV e est' é pola casa molhada en que as mete, na estrabaria.

1446 PedroPort [V1037], v. 4: <est e> V Alvar Rodriguez, monteiro maior, sabe ben que lhi á' 1-Rei desamor, porque lhe dizen que é mal feitor na sa terra; est' é cousa certa ca diz que se quer ir...

47 A consideración da forma éste esixe unha mudanza de puntuación:

Rei d'Aragon, rei do bon sén,

rei de prez, rei de todo ben éste: rei d'Aragon, de pran. 


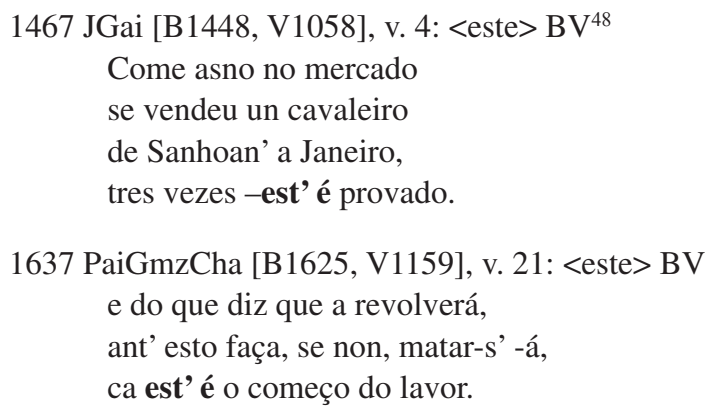

\section{Cabo}

O inventario da forma éste na lírica profana galego-portuguesa podería ser aínda máis amplo se considerarmos lecturas alternativas ás tradicionais que estabelecen formas demostrativas de primeira persoa que poden encubrir directamente a forma éste ou unha crase ést' + vogal. Véxase, por exemplo, a real posibilidade de editar "[É] esta coita, que mi a morte ten / tan chegada..." (1056 MartPrzAlv [B1054, V644], v. 13) como "[E] ést' a coita, que mi a morte ten / tan chegada...", con aparición de ést' e deslocamento do acento á segunda sílaba, frecuente en toda a cantiga. E o mesmo acontece en contextos tradicionalmente lidos como $m$ 'é esta que poden ser interpretados como me ést' a: 551 Den [B534, V137], v. 28: “ca morte m'é esta vida" vs. "ca morte me ést' a vida"; 946 JAi [B943, V531], v. 7: "Tan grave m' é esta coita en que me ten" vs. "Tan grave me ést' a coita en que me ten". Ou, por pór algúns exemplos de teor aínda máis interpretativo, un verso como "ca esta morte non é jograria" (398 JGarGlh? [A238], v. 14) sempre podería ser lido como “ca ést' a mort' e non é jograria", do mesmo modo que "este pesar é pesar con razon" pode ser transcrito tamén como "éste pesar, e pesar con razon” (1533 PMaf [B1514], v. 16).

Algo semellante pode acontecer coa forma verbal está, tamén susceptíbel nalgúns contextos de ser lida como unha crase de éste, como, por exemplo, estabelece Cohen (2005: 214) na cantiga 741 RoEaVasc [B726, V327], v. 4, a través dunha adición para resolver a hipometría do verso: "mais en vossa prison / ést' [or]a quite por vós d' outra ren".

Finalmente, aínda fican outras formas de éste que por veces foron hipotizadas para resolver versos hipométricos ${ }^{49}$. Cf., por exemplo, "se non a mi, dizen que é[ste] mal

\footnotetext{
${ }^{48}$ Contra a práctica xeral, neste caso Lapa (1970: 303) interpreta a presenza de éste, que é, evidentemente, posíbel.

49 Ás veces son solucións extremadamente hipotéticas para resolver pasaxes manuscritas deturpadas: "e por est', amiga[s], ést[e te]udo" (784 JGarGuilh [B787/V371], v. 12), que, na edición de Rip Cohen presenta outro texto: "e por est', amiga<s>, é <a>budo" (Cohen 2005: 251).
} 
/ mias amigas e que faço mal sén" (742 RoEaVasc [B727, V328], v. 3); "Qual é[st' o] voss' amigo que mi vos pedia?" (663 NuFdzTor [B648, V249], v. 4), esixido polo paralelismo co v. 2; "ou que [ést]' est' ou por que o fazedes" (823 AfEaCot [B825, V411], v. 18), verso paralelo ao primeiro do refrán da cantiga: "que ést' aquest' ou por que o fazedes".

Mais tamén é certo que a revisión do corpus tamén implica a eliminación de formas de éste que son produto de opcións editoriais discutíbeis ou de lecturas probabelmente erradas: Cohen (2005: 342), polo paralelismo co primeiro verso da estrofa anterior, edita "Falarei con el, pois está [a]ssi" o verso tradicionalmente estabelecido como "Falarei con el[e], pois ést' assi” (1004 RoiMrzUlv [B1000, V589], v. 15). E noutros casos, son simples erros de lectura, como a forma editada por Lang ("est a molher") seguindo V, cando en B aparece a lección correcta: “... mais non vos direi eu qual / é a molher; mais tanto vos direi” (528 Den [B520a, V113, T7], v. 4).

A frecuencia da documentación de éste (quer na súa forma plena, quer na que presenta crase) desmente, pois, o carácter excepcional atribuído a esta forma na maioría das edicións, mostrando que é moito máis frecuente do que recollen os textos críticos ou os glosarios, ao tempo que tamén se pode documentar excepcionalmente perante vogal. É máis, a distribución de éléste nas Cantigas de Santa Maria ${ }^{50}$, que non son obxecto deste relatorio, confirma exactamente o mesmo comportamento das dúas variantes verbais en causa ${ }^{51}$ : a forma éste na súa forma plena é máis frecuente na poesía relixiosa de Afonso $\mathrm{X}$ do que na lírica profana, pois localizamos até trinta e seis casos perante consoante ${ }^{52}$, a carón de cinco contextos en que éste aparece perante $\operatorname{vogal}^{53}$.

\footnotetext{
50 Seguimos a clásica edición de Mettmann (1986-1989), así como a súa numeración dos versos.

51 Aínda hai que acrecentar algún contexto máis en que a forma <est $>$ dos manuscritos tamén debe ser corrixida para ést[e] por necesidades métricas (véxase 149.44, 185.10, 297.11, 386.56). Considérese aínda un caso de [éste] en 165.56.

52 Véxase CSM A.22, 46.47, 48.11, 95.60, 121.41, 175.7, 199.14, 219.12, 221.8, 247.27, 250.8 e 10, $271.43,272.35,273.3$ (=r1), 275.21, 292.23, 295.25, 315.41, 322.3 (=r1) e 43, 328.10, 328.25, 332.13 e $16,340.43$, 344.6, 352.38, 358.8, 366.41, 368.41, 371.7, 372.3 (=r1), 385.27, 393.8, 414.4.

53 Véxase CSM 31.8, 220.8, 225.11, 328.12, 364.8382 .4 (=r1). Para alén destes casos, rexístranse tamén formas con crase da vogal final perante as formas do artigo $o, a$ (CSM B.17, 135.101, 274.30, 328.23), do indefinido hũa (CSM 306.20), dos adverbios aqui e assi (CSM 402.21, 425.37), da prep. $a($ CSM 142.51), da conx. $e$ (CSM 261.61, 380.47, 402.20, 418.18) e do participio apparellada (CSM 297.15).
} 


\section{Referencias bibliográficas}

Barbieri, M. (1980): "Le poesie di Roy Paez de Ribela", Studi Mediolatini e Volgari, 27: 7-104.

Blasco, P. (1984): Les chanson de Pero Garcia Burgalês, troubadour galicienportugais du XIII ${ }^{e}$ siècle (Paris: Fundação Caloute Gulbenkian / Centro Cultural Português).

Brea, M. (coord.) (1996): Lírica Profana Galego-Portuguesa (Santiago de Compostela: Xunta de Galicia).

Cancioneiro da Biblioteca Nacional (Colocci-Brancuti). Cód. 10991 (1982) (Lisboa: Biblioteca Nacional / Imprensa Nacional-Casa da Moeda).

Cancioneiro Português da Biblioteca Vaticana (Cod. 4803) (1973) (Lisboa: Centro de Estudos Filológicos / Instituto de Alta Cultura).

Cohen, R. (2003): 500 Cantigas d'Amigo (Lisboa: Campo das Letras).

Cunha, C. Ferreira da (1982): Estudos de Versificação Portuguesa (Séculos XIII a XVI) (Paris: Fundação Calouste Gulbenkian / Centro Cultural Português).

Ferreira, M. P. (2005): Cantus Coronatus. 7 Cantigas d'El-Rei Dom Dinis (Kassel: Reichenberger).

Ferreiro, M. / Martínez Pereiro, C. P. / Tato Fontaíña, L. (eds.) (2007): Normas de edición para a poesía trobadoresca galego-portuguesa / Guidelines for the Edition of Medieval Galician-Portuguese Troubadour Poetry (A Coruña: Universidade da Coruña).

Fregonese, R. (ed.): Joham Vaasquiz de Talaveyra, Poesie e Tenzoni (Milano: Edizioni Spolia).

Juárez, A. (1992): Pero da Ponte (Granada: TAT).

Lang, H. R. (1972) [1894]: Das Liederbuch des Königs Denis von Portugal (New York: Georg Olms Verlag).

Lapa, M. Rodrigues (1970) [1965]: Cantigas d'Escarnho e de Mal Dizer dos Cancioneiros Medievais Galego-Portugueses (Vigo: Galaxia).

Lopes, G. Videira (2002): Cantigas de Escárnio de Maldizer dos Trovadores e Jograis Galego-Portugueses (Lisboa: Estampa).

Lorenzo, R. (ed.) (1974): La traducción gallega de la Crónica General y de la Crónica de Castilla. Vol. II: Glosario (Ourense: Instituto de Estudios Orensanos "Padre Feijoo").

Maia, C. de Azevedo (1986): História do Galego-Português. Estado Linguístico da Galiza e do Noroeste de Portugal desde o século XIII ao século XVI (Coimbra: Instituto Nacional de Investigação Científica).

Marroni, G. (1968): “Le poesie di Pedr' Amigo de Sevilha", Annali dell'Istituto Universitario Orientale, 10: 189-340. 
Mettmann, W. (1972): Alfonso X el Sabio. Cantigas de Santa Maria. Vol. IV (Glossário) (Coimbra: Universidade de Coimbra).

Mettmann, W. (ed.) (1986-1989): Alfonso X el Sabio. Cantigas de Santa Maria. 3 vols. (Madrid: Castalia).

Michaëlis de Vasconcelos, C. (1990) [reimpressão facsimilada da ed. de Halle, 1904]: Cancioneiro da Ajuda. 2 vols. (Lisboa: Imprensa Nacional / Casa da Moeda).

Montero Santalla, J. M. (2001): As Rimas da Poesia Trovadoresca Galego-Portuguesa: Catálogo e Análise. Tese de Doutoramento (inédita), Universidade da Coruña.

Nobiling, O. (1907): "Zu Text und Interpretation des 'Cancioneiro da Ajuda'”, Romanische Forschungen, 23: 339-385.

Nobiling, O. (1908): “As cantigas de D. Joan Garcia de Guilhade, Trovador do século XIII", Romanische Forschungen, 25: 641-719.

Nunes, J. J. (1972) [1932]: Cantigas de Amor dos Trovadores Galego-Portugueses (Lisboa: Centro do Livro Brasileiro).

Nunes, J. J. (1973) [1926-1928]: Cantigas de Amigo dos Trovadores Galego-Portugueses. 3 vols. (Lisboa: Centro do Livro Brasileiro).

Pagani, W. (1971): "Il Canzoniere di Estevan da Guarda", Studi Mediolatini e Volgari, 19: 53-179.

Panunzio, S. (1991): Pero da Ponte. Poesías (Vigo: Galaxia).

Paredes, J. (2001): El cancionero profano de Alfonso X el Sabio. Edición crítica con introducción, notas y glosario (Roma: Japadre).

Rodríguez, J. L. (1980): El cancionero de Joan Airas de Santiago. Anexo 12 de Verba (Santiago de Compostela: Universidade de Santiago de Compostela).

Spampinato Beretta, M. (1987): Fernan Garcia Esgaravunha. Canzoniere (Napoli: Liguori Editore).

Stegagno Picchio, L. (ed.) (1968): Martin Moya, Le poesie (Roma: Edizioni dell'Ateneo). 